\title{
INTERDISCIPLINARY COLLABORATIVE RESEARCH: AN IMMEDIATE NEED IN TODAY'S PHARMACEUTICAL RESEARCH
}

Dear Reader,

While India has acquired global recognition as a reliable source of high quality, impurity free active pharmaceutical ingredients (APIs) and generic pharmaceuticals, Indian pharmaceutical $R \& D$ has to go a long way to enter the global pharmaceutical R\&D map. The 2016 OECD report "Measuring Science Technology and Innovation" (https://www.oecd.org/sti/STI-Stats-Brochure.pdf) has a large compilation of data on $R \& D$. India hardly finds a place in this study, except on the use of the internet \& IT. As confirmed by the OECD data in $1960,70 \%$ or more of all $R \& D$ spend globally was from

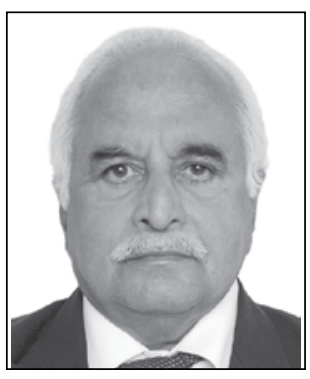
Government funds. India claims to have the largest chain of $R \& D$ laboratories in the world under the CSIR/DSIR umbrella. Between 1960 to 2017, the contribution of CSIR laboratories, including once-reputed laboratories such as CDRI, Lucknow and IIIM, Jammu, to pharmaceutical research has only gone down.

Over the years, $R \& D$ funding to pharmaceutical companies from the government and others has only been dwindling. It is, therefore, becoming abundantly clear that pharmaceutical (and biotechnology) $R \& D$ has to be driven by the pharmaceutical industry. Can the pharmaceutical industry drive the R\&D by itself? With the current trend of future molecules moving from chemistry to biotechnology, challenges have been mounting for pharmaceutical corporations to find the road map for innovation to keep pace with the rest of the world, leave alone OECD countries.

The innovation challenges for the pharmaceutical industry get compounded by the NGO driven NPPA model for price control in India. Pharmaceutical R\&D has no sympathiser, leave alone a Godfather ministry in India, inspite of pharmaceutical exports being one of the largest from India.

It is in this context, that the Industry-Academia collaborations for pharmaceutical and biotech $R \& D$ has become a Hobson's choice. Industry has no option than to tie up with academia, especially for tapping, training and utilising the human $R \& D$ resources in Academia. Academic research in India (and generally all over the world) is considered unfit to be adopted for industry to commercialize as such. Industry has to train skilled and talented academics to take up innovative projects needed by industry. Industry also has to hand-hold and guide academia to plan projects, develop $R \& D$ pipelines and convert the processes and products to commercial outcomes. To achieve this objective, $R \& D$ in industry must be able to attract and retain skilled researchers and have the patience to fund the research to take it eventually to logical commercial conclusions. Academia need to shed the current on-site politics and ego-based one-upmanships and crab mentalities. Academic R\&D leaders and researchers need to adopt and acquire work disciplines and productive styles and practices akin to industrial R\&D. GLP and General Regulation on Data Protection has to be adopted by academic institutions.

In these times, when chemical blockbusters are becoming slowly extinct and more and more biologics and genomic drugs are coming of age, pharmaceutical industry needs to find $R \& D$ partners within the medical fraternity in public hospitals too. Bio-medical research, which will move forward in the coming years will need close co-ordination of industry with academia and medical fraternity (and government institutions to the extent available and forthcoming).

NMR arrived in India in the early sixties of the last century for chemical and pharmaceutical research. HPLC, LCMS and X-ray crystallography came into pharma R\&Ds a couple of decades later. These instrumental techniques are being routinely used by Research Laboratories as pharmaceutical R\&D has been relying increasingly on instrumentation and IT support in recent years. Advanced Spectroscopy, Automated Chromatography, Crystallography and the like have been driving as well as supporting pharmaceutical 
$R \& D$ over the last 50 to 60 years. Advances in integrated homology analysers and gene amplification detectors etc. could increasingly assist future bio-pharma $R \& D$ projects and platforms.

Plant based drug discovery research dominated the early breakthroughs in pharmaceuticals. From digitalis in 1785 to caffeine, codeine, morphine, quinine, reserpine, scopolamine, paclitaxel, (taxol), theophylline to vinca alkaloids, it has been a long and distinguished journey. However, of late, the undue domination of biodiversity issues, traditional knowledge protection and NGO driven impractical benefit sharing models and high royalty demands are discouraging $R \& D$ initiatives in natural products. Research in biological resources also need support from synthetic chemistry laboratories as well as analytical, pharmacology, toxicology and clinical evaluation streams. Of late, such collaborative, net-worked, knowledge sharing practices have died down and every pharmaceutical researcher is turning to live and work in his own island. The Indian pharmaceutical industry needs to move on similar biologics ('mabs' as example). Opening up of metabolic pathways, advances in protein chemistry and data from genomic sequencing are all the emerging frontiers of tomorrow. Nano particles based research for resolving future drug delivery problems and for cell specific targeted drug development leading to reduced side effects, will also need collaborative initiatives. From targeted delivery systems, implants, coated stents and needleless injections, pharmaceutical research is moving on to 3D printed drugs (such as FDA approved SPRITAM) which delivers the dose layers till the needful peak is achieved. 3D printed oral dosage forms in different shapes and designs are also evolving. Newer processes such as "hot melt extrusion" are also emerging. 'Nanobots' are also on the anvil as a collaborative effort with robotics for drug delivery. All these writings on the wall call for increasingly enhanced levels of networking of bio-pharma researchers with industry and academia with IT, analytics, diagnostics, medical researchers, genomic, robotics and, in short, "whomsoever who can deliver most effectively".

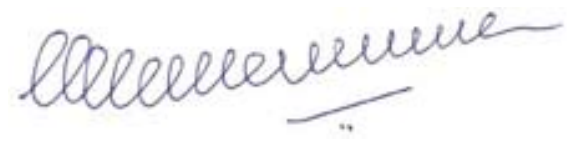

Dr. Gopakumar G. Nair

Editor, Indian Drugs 